\title{
ANÁLISE DE ACESSIBILIDADE EM EDIFÍCIO PÚBLICO
}

Ligia Maria Gomes Grieco" ; Priscila Lima de Oliveira' ${ }^{2}$ Carlos Roberto Mangussi Filho ${ }^{3}$; André Luiz Alves da Silva ${ }^{1}$; Carlos Roberto Mangussi'; ${ }^{2}$ Luis César de Oliveira ${ }^{3}$;

1,2,3 Universidade de Uberaba

ligiamggrieco@gmail.com; acessibilidade.ic@gmail.com

\section{1 - Introdução}

A acessibilidade é definida como, a condição para utilização, com segurança e autonomia, total ou assistida, dos espaços, mobiliários e equipamentos urbanos, das edificações, dos serviços de transporte dos dispositivos, sistemas e meios de comunicação e informação, por pessoa portadora de deficiência ou mobilidade reduzida (Decreto 5.296/2004 - CAP.III Art.8), no uso da atribuição que lhe confere o art. 84, inciso IV, da Constituição, os e tendo em vista o disposto nas Leis no 10.048 , de 8 de novembro de 2000, e 10.098, de 19 de dezembro de 2000.

A aplicação desse conceito garante o direito de ir e vir. Destaca-se a partir de então, os edifícios públicos, que devem ser acessível a toda população, e devido à mobilidade reduzida, exclui uma parcela dos indivíduos das atividades ali desenvolvidas.

Esse artigo analisa os parâmetros físicos do mercado público da cidade de Uberaba, inaugurado no ano de 1924 e tombado como patrimônio histórico pelo CONDEPHAU Conselho Deliberativo Municipal do Patrimônio Histórico, Artístico de Uberaba, sendo considerado um ponto tradicional de comércio e relações interpessoais da cidade.

$\mathrm{Na}$ área de Engenharia Civil, problematizaremos o local com auxílio de normas técnicas de acessibilidade, em especial a NBR - 9050, esta norma estabelece critérios e parâmetros técnicos a serem observados quando do projeto, construção, instalação e adaptação de edificações, mobiliário, espaços e equipamentos urbanos às condições de acessibilidade.

Analisando 0 ambiente externo que fornece acesso público ao edifício, ambiente interno e sanitários, logo, sugestionaremos soluções para promover a mobilidade do edifício auxiliando o bem estar psicossocial da população envolvida e enriquecendo o patrimônio municipal.

Os objetivos principais são, identificar as dificuldades encontradas por portadores de deficiência ou com mobilidade reduzida em acessar e se locomover no ambiente estudado e indicar as possíveis soluções em conformidade com os parâmetros normativos, devido ao tombamento, desenvolver projetos que apresentem sugestões para solução sem alterações na arquitetura do edifício objeto de estudo.

\section{2 - Materiais e métodos}

O estudo a ser realizado abordará os seguintes itens para o levantamento dos parâmetros físicos do espaço urbano do ambiente e seu entorno:

- Equipamentos que a utilizar:

Pranchetas;

Trenas métrica e eletrônica;

Câmera fotográfica;

Computadores;

- Levantamento histórico:

Levantamento da arquitetura do espaço desde sua inauguração até a atualidade, estudo do projeto original e posteriores reformas;

- Análise dos parâmetros físicos internos:

Medidas de todos os compartimentos onde haja possibilidade de passagem;

Descrição dos materiais utilizados na construção;

Estudo das escadas de acesso nos quesitos conforto e segurança;

Verificação de pontos de fornecimento de água potável para bebedouros;

Estudo das instalações sanitárias femininas e masculinas;

- Análise do ambiente externo que dá acesso ao mercado:

Análise do processo de evolução urbana do local;

Levantamento das dimensões de vias locais, passeios, meio fio, sarjetas de coleta de águas pluviais;

Estudo do tipo de pavimentação;

Verificação do sistema de transporte coletivo do local, se o mesmo, atende as pessoas portadoras de deficiência ou mobilidade reduzida;

Verificação da existência e/ou número de vagas especiais no estacionamento;

- Levantamento fotográfico dos ambientes estudados 
- Análise da conformidade dos ambientes com as normas brasileiras de acesso:

Verificar se os ambientes onde já haja adaptação estão de acordo;

Apontar quais as deficiências em acessibilidade encontradas;

- Sugestionar soluções:

Realização de projetos que apontem possíveis soluções que possam tornar o prédio acessível sem comprometer a arquitetura histórica;

\section{3 - Resultados e discussão}

Os principais resultados esperados são, levantamento de dados técnicos e parâmetros físicos da atual situação de um mercado público, ambiente interno, sanitários e áreas externas de acesso ao edifício, em relação a acessibilidade, e em conformidade com as normatizações, desenvolvimento de projetos para apresentação de sugestões que solucionem a dificuldade de acesso, de acordo com o inventário de tombamento do CONDEPHAU, sem alterações na arquitetura, utilizando normas brasileiras de acesso.

\section{4 - Considerações Finais}

O principal resultado esperado é a conscientização dos profissionais de Engenharia Civil sobre a importância das normas de acessibilidade e sua respectiva aplicação em suas obras, o artigo é uma maneira de dizer a esses profissionais que eles constroem algo além de paredes, eles instituem e resgatam valores.

\section{5 - Referências} BRASIL.

Constituição

(1988).

Constituição da República Federativa do

Brasil: promulgada em 5 de outubro de 1988. Organização do texto: Juarez de Oliveira. 4. ed. São Paulo: Saraiva, 1990. (Série Legislação Brasileira).

BRASIL. Decreto, n. 5296, de 2 de dezembro de 2004. Para fins de acessibilidade. Lex: Coletânea de Legislação e Jurisprudência, São Paulo.

ASSOCIAÇÃO BRASILEIRA DE NORMAS TÉCNICAS. Acessibilidade a edificações, mobiliário, espaços e equipamentos urbanos: ABNT NBR-9050. Rio de Janeiro, 2004. 1 p.

\section{6 - Agradecimentos}

Agradecemos aos nossos orientadores, que nos auxiliam em todos os momentos. Agradecemos também, a Universidade de Uberaba pela oportunidade de conhecimento que nos foi dada, onde com mero esforço e dedicação de ambos, podemos nos enriquecer e amadurecer nossos conceitos, além de outras perspectivas sobre o tema, gerando uma bela pesquisa. 
